\title{
Results of reference pricing and reimbursement discount rate schemes of Turkey
}

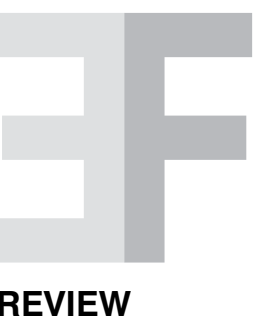

\author{
Guvenc Kockaya ${ }^{1}$, Kagan Atikeler ${ }^{2}$, Esin Tuna 2, Pelin Kllıc ${ }^{3}$, Pelin Tanyeri ${ }^{4}$, \\ Nurcan Umman ${ }^{3}$, İsmail Mert Vural ${ }^{3}$, Omer Altun ${ }^{3}$, Akif Akbulat $^{3}$, Guven Artiran ${ }^{3}$, \\ Ercan Simsek ${ }^{3}$, Hakkı Gursoz ${ }^{3}$, Saim Kerman ${ }^{3}$ \\ Health Economics and Policy Association, Ankara, Turkey \\ Hacettepe University, Ankara, Turkey \\ Turkish Medicines and Medical Device Agency, Ankara, Turkey \\ Sakarya University, Sakarya, Turkey
}

\begin{abstract}
OBJECTIVES: General Directorate of Pharmaceuticals and Pharmacy (IEGM) is responsible for setting all prices for human medicinal products. The reference pricing system is used for setting these prices. Reference countries are reviewed annually and may be subject to certain alterations. There were 5 reference countries in 2009: Spain, Italy, Germany, France and Greece. The aim of this study is to show the distribution of reference countries which were used for reference pricing. METHODS: The price list of pharmaceuticals which was published by IEGM on 15.04.2011 was used for analysis. Distribution of reference countries and prices were evaluated.

RESULTS: Prices of 6,251 generic and 3,703 original products were set according to the price list. 5,283 of generics and 3,306 of originals were in the positive list for reimbursement. Reference pricing was used for 2,352 generics and 2,281 originals. Prices of the remaining were set outside of reference pricing. 32 different countries were used for reference pricing. Italy was the most popular country for reference pricing. Even if it was not a reference country, Germany was used in some of the pharmaceuticals. The average reimbursement discount rate and price were $24.43 \%$ and $249 \mathrm{TL}$, respectively. There were no colerations between price and reimbursement discount rate, or reference country and reimbursement rate. CONCLUSION: It has been shown that Italy has the highest impact on the pricing of all pharmaceuticals in Turkey. Even if it was not a reference country, Germany showed to affect pharmaceuticals more than other countries which were also not used for reference pricing. Even if reimbursement discount rates are stated by the Social Security Institution (SGK), there are different discount rates for pharmaceuticals. The analysis stated that there were correlation between price, country and discount rates. This analysis is first for the literature. Further analysis is necessary in the light of price changes and newly launched pharmaceuticals
\end{abstract}

\section{Keywords}

Reference pricing, Policy analysis; Reimbursement discount rate

\section{INTRODUCTION}

The international reference pricing system is used for setting prices for human medicinal products and controlling health care expenditure.

The international reference pricing system is started to be implemented in Turkey since 2004. Actually this system has been started, as one of the results of the Health Transformation Programme (HTP) which has started in 2002 with the new government in Turkey. It has been aiming to solve the problems of the health sector which have not been solved before, and which grew as they were not solved therefore which are perceived as never changeable. Health Transformation Programme (HTP) consists of 8 components, which have been formed to cover the sector with all its dimensions. Each component is matched with other component and covers the solutions appropriate for the program and one of component was "Access to Effective Information at Decision Making Process which called Health Information System". With HTP access to health has increased at a large extent and as a result of this situation Turkish total health expenditures has increased past few years and it was 76 billion Turkish Liras (30.4 billion Euros) for year 2011. Total pharmaceutical expenditure was 15.6 billion Turkish Liras (6.24 billion Euros) which is around $20 \%$ of Total Health Expenditures (THE) of Turkey of same year.

In Turkey, General Directorate of Pharmaceuticals and Pharmacy (IEGM) is responsible for setting all prices for human medicinal
Corresponding author Guvenc Kockaya guvenckockaya@yahoo.com

\section{Disclosure}

No funding was received

for the manuscript 
products. Reference country prices set the basis for pricing of medicinal products licensed in Turkey. European Union (EU) Member States and Candidate Countries for whom membership is guaranteed within a year may be selected as reference countries for pricing estimates. Reference countries are reviewed annually and may be subject to certain alterations. There were 5 reference countries in 2011: Spain, Italy, Germany, France, and Greece [1,2].

\begin{tabular}{lcc}
\hline & In reference pricing & Out reference pricing* \\
\hline Generics $(\mathrm{TL})$ & 54.12 & 11.77 \\
Originals $(\mathrm{TL})$ & $248 ., 55$ & 20.2 \\
\hline
\end{tabular}

Table I. Average prices (numbers are rounded)

* Price determined with special conditions.
For original products, companies may request up to a maximum of $100 \%$ of the reference price. For those products, to which there exists no original formulation within Turkey or for generic products, companies may request up to a maximum of $66 \%$ of the reference price for the original product officially issued by IEGM. The Social Security Institution (SGK) determines the discount rate for government reimbursement. Original products must give $11 \%$ discount for be listed in the positive list for reimbursement. This discount rate is for the first year; it shall be increased to $23 \%$ in following year. Generic products must provide $23 \%$ discount from the first year. On the other hand, there is a global budget agreement with pharmaceutical companies. If the global budget for pharmaceuticals is exceeded, the government may take

\begin{tabular}{|c|c|c|c|c|c|}
\hline & $\begin{array}{c}\text { In all pharmaceuticals } \\
(\%)\end{array}$ & $\begin{array}{c}>200 \mathrm{TL} \\
(\%)\end{array}$ & $\begin{array}{c}>100 \mathrm{TL}, \leq 200 \mathrm{TL} \\
(\%)\end{array}$ & $\begin{array}{c}>50 \mathrm{TL}, \leq 100 \mathrm{TL} \\
(\%)\end{array}$ & $\begin{array}{c}\leq 50 \mathrm{TL} \\
(\%)\end{array}$ \\
\hline Italy & 24.47 & 16.26 & 31.26 & 23.08 & 25.36 \\
\hline Spain & 21.96 & 14.88 & 22.91 & 22.24 & 23.12 \\
\hline Greece & 19.69 & 27.85 & 15.51 & 20.40 & 18.57 \\
\hline France & 11.8 & 12.11 & 13.13 & 14.05 & 11.18 \\
\hline Portugal & 8.7 & 7.44 & 5.97 & 7.69 & 9.56 \\
\hline Germany & 3.7 & 4.67 & 1.91 & 3.01 & 3.92 \\
\hline Others & 9.58 & 16.78 & 9.31 & 9.53 & 8.28 \\
\hline
\end{tabular}

Table II. Ranking of used countries in reference pricing of all pharmaceutical drugs (numbers are rounded)

\begin{tabular}{|c|c|c|c|c|c|}
\hline & $\begin{array}{c}\text { In original } \\
\text { pharmaceuticals (\%) }\end{array}$ & $\begin{array}{c}>200 \mathrm{TL} \\
(\%)\end{array}$ & $\begin{array}{c}>100 \mathrm{TL}, \leq 200 \mathrm{TL} \\
(\%)\end{array}$ & $\begin{array}{c}>50 \mathrm{TL}, \leq 100 \mathrm{TL} \\
(\%)\end{array}$ & $\begin{array}{c}\leq 50 \mathrm{TL} \\
(\%)\end{array}$ \\
\hline Greece & 24.25 & 31.51 & 26.79 & 30.62 & 19.63 \\
\hline Spain & 19.16 & 15.97 & 17.70 & 22.80 & 20.09 \\
\hline Italy & 18.37 & 12.82 & 21.05 & 17.92 & 19.70 \\
\hline France & 11.16 & 8.82 & 12.44 & 7.82 & 12.62 \\
\hline Portugal & 10.59 & 7.98 & 6.22 & 8.47 & 12.77 \\
\hline Germany & 5.45 & 5.67 & 3.83 & 4.89 & 5.76 \\
\hline Others & 11.03 & 17.23 & 11.94 & 7.49 & 9.42 \\
\hline
\end{tabular}

Table III. Ranking of used countries in reference pricing of original pharmaceuticals (numbers are rounded)

\begin{tabular}{|c|c|c|c|c|c|}
\hline & $\begin{array}{c}\text { In generic } \\
\text { pharmaceuticals (\%) }\end{array}$ & $\begin{array}{c}>200 \mathrm{TL} \\
(\%)\end{array}$ & $\begin{array}{c}>100 \mathrm{TL}, \leq 200 \mathrm{TL} \\
(\%)\end{array}$ & $\begin{array}{c}>50 \mathrm{TL}, \leq 100 \mathrm{TL} \\
\text { (\%) }\end{array}$ & $\begin{array}{c}\leq 50 \mathrm{TL} \\
(\%)\end{array}$ \\
\hline Italy & 30.38 & 32.35 & 41.43 & 28.52 & 29.23 \\
\hline Spain & 24.68 & 9.80 & 28.10 & 21.65 & 25.63 \\
\hline Greece & 15.28 & 10.78 & 4.29 & 9.52 & 17.79 \\
\hline France & 12.51 & 27.45 & 13.81 & 20.62 & 10.13 \\
\hline Portugal & 6.94 & 4.90 & 5.71 & 6.87 & 7.21 \\
\hline Germany & 2.04 & 0 & 0 & 1.03 & 2.57 \\
\hline Others & 9.17 & 14.71 & 6.67 & 11.68 & 7.44 \\
\hline
\end{tabular}

Table IV. Ranking of used countries in reference pricing of generic pharmaceuticals (numbers are rounded) 
the exceeded budget back from all manufacturers. In the year 2010, the government increased the discount rate to an additional $9.5 \%$ (in total $20.5 \%$ and $32.5 \%$ ) depending on the excess global budget. In some cases, even pharmaceutical companies give more discount rate for be listed in the positive list; sometimes government decreases discount rates to $4 \%$ for exceptional drugs like orphan medicinal products $[1,2]$.

The aim of this study is to show the result of IEGM's reference pricing schemes and SGK's discount schemes.

\section{METHOD}

The price list of pharmaceutical drugs which was published by IEGM on 15.04.2011 and the discount rate list which was published by SGK on 01.05.2011 were used for the analysis. Distribution of reference countries, prices and discount rates were evaluated. 2.50 was used as the exchange rate of converting Turkish Liras (TL) to Euros.

\section{RESULTS}

\section{Reference price analysis}

According to the price list, prices of 6,251 generic and 3,703 original products were set. 5,283 of generics and 3,306 of originals were in the positive list for reimbursement. Reference pricing was used for 2,352 generics and 2,281 originals. Prices of the remaining were set outside of reference pricing. Average prices for generics and originals which are priced by reference pricing were 54,12 TL and 248.55 TL, respectively (Table I).

32 different countries were used for reference pricing. The most popular country for reference pricing in all pharmaceuticals and generics $(24.47 \%)$ was Italy. Italy was followed by Spain $(21.96 \%)$, Greece $(19.69 \%)$, France (11.8\%), and Portugal (8.7\%) (Table II).

Even if it was not a reference country, Germany was used in $3.71 \%$ of pharmaceuticals. The other 25 countries were used by $13.29 \%$. However the ranking was changed only in pharmaceuticals with prices above 200 Turkish Liras (TL) or original pharmaceuticals; Greece was the most popular country in these rankings by $27.85 \%$ and $24.25 \%$, respectively. Greece was the most popular country for reference pricing in originals, except those with a price under $50 \mathrm{TL}$. Although, Germany was not a reference country, Germany was used in $5.45 \%$ of original pharmaceuticals. Other 25 countries were used by $11.03 \%$ (Table III).

Percentage of Italy in generics were $30.38 \%$. The ranking in generics is same as all pharmaceuticals with different percentages (Table IV).

\begin{tabular}{lcccc}
\hline & $\begin{array}{c}\mathbf{2 0 0} \mathrm{TL} \\
\mathbf{( \% )}\end{array}$ & $\begin{array}{c}\mathbf{> 1 0 0} \mathrm{TL}, \\
\mathbf{2 0 0} \mathrm{TL}(\boldsymbol{\%})\end{array}$ & $\begin{array}{c}\mathbf{> 5 0} \mathrm{TL}, \\
\mathbf{1 0 0} \mathrm{TL}(\boldsymbol{\%})\end{array}$ & $\begin{array}{c}\mathbf{5 5 0} \mathrm{TL} \\
\mathbf{( \% )}\end{array}$ \\
\hline Originals & 20.9 & 9 & 13 & 56.4 \\
Generics & 4.3 & 8.9 & 12.3 & 74.3 \\
\hline
\end{tabular}

Table V. Ranking of originals and generics depending on price limits (numbers are rounded)

\begin{tabular}{lccc}
\hline & All (TL) & Originals (TL) & Generics (TL) \\
\hline Greece & 239.33 & 367.35 & 42.49 \\
Spain & 108.78 & 198.45 & 41.76 \\
France & 121.12 & 183.5 & 65.17 \\
Portugal & 130.78 & 181.74 & 58.06 \\
Italy & 91.12 & 149.11 & 57.38 \\
Germany & 107.44 & 141.14 & 20.17 \\
Others & 30.94 & 79.96 & 10.28 \\
\hline
\end{tabular}

Table VI. Average prices list depeding on reference country (numbers are rounded)

Prices of the most of the pharmaceuticals, both generics and originals, are below 50 TL. On the other hand, the price of $20.9 \%$ of original pharmaceuticals are above $200 \mathrm{TL}$, against $4.3 \%$ of generics (Table V).

Even though pharmaceuticals which are priced with Greece, have the highest average price in originals with $367,35 \mathrm{TL}$, pharmaceuticals which are priced with France, have the highest average price in generics with 65.17 TL (Table VI).

\section{Reimbursement discount rate analysis}

Discount rates were analysed only for originals which are covered with government reimbursement and priced due the reference pricing scheme, as the discount rate of generics are similar and are fixed with rules. The average reimbursement discount rate and price were $24.43 \%$ and $249 \mathrm{TL}$, respectively. Reimbursement discount rate of $43 \%$ of originals were between 20.50-32.50\%. The average discount rate and price were $21.61 \%$ and 153.53 TL, respectively (Table VII). In addition, discount rates were evaluated for different price limits and reference countries.

\begin{tabular}{lccc}
\hline $\begin{array}{c}\text { Discount rate } \\
(\%)\end{array}$ & $\begin{array}{c}\text { Percentage of } \\
\text { pharmaceuticals (\%) }\end{array}$ & $\begin{array}{c}\text { Average } \\
\text { discount (\%) }\end{array}$ & $\begin{array}{c}\text { Average } \\
\text { price (TL) }\end{array}$ \\
\hline$<11$ & 1 & 5.63 & 163.45 \\
$\geq 11,<20.50$ & 15 & 11.66 & 318.45 \\
$\geq 20.50,<32.50$ & 44 & 21.61 & 153.53 \\
$=32.50$ & 37 & 32.50 & 351.60 \\
$>32.50$ & 3 & 42.12 & 222.79 \\
\hline
\end{tabular}

Table VII. List of reimbursement discount rates (numbers are rounded) 


\begin{tabular}{lccc}
\hline Price limit (TL) & Percentage of pharmaceuticals (\%) & Average discount (\%) & Average price (TL) \\
\hline$<5$ & 56 & 23.40 & 23.46 \\
$\geq 50,<100$ & 13 & 26.55 & 71.75 \\
$\geq 100,<150$ & 5 & 25.10 & 120.32 \\
$\geq 150,<200$ & 4 & 25.80 & 175.33 \\
$\geq 200,<1,000$ & 15 & 25.56 & 468.78 \\
$\geq 1,000$ & 6 & 25.36 & 2581.94 \\
\hline
\end{tabular}

Table VIII. List of reimbursement discount rate in different prices (numbers are rounded)

\begin{tabular}{|c|c|c|c|c|c|c|}
\hline \multirow{2}{*}{$\begin{array}{l}\text { Referenced } \\
\text { country }\end{array}$} & \multirow{2}{*}{$\begin{array}{c}\text { Average } \\
\text { discount (\%) }\end{array}$} & \multicolumn{5}{|c|}{ Percentage in discount rates (\%) } \\
\hline & & $<11$ & $\geq 11,<20.50$ & $\geq 20.50,<32.50$ & $=32.50$ & $>32.50$ \\
\hline France & 23.19 & 1 & 23 & 37 & 37 & 2 \\
\hline Greece & 26.96 & 0 & 10 & 37 & 48 & 5 \\
\hline Italy & 24.19 & 1 & 10 & 54 & 30 & 5 \\
\hline Portugal & 24.56 & 2 & 13 & 45 & 37 & 3 \\
\hline Spain & 25.06 & 0.5 & 8.5 & 55 & 34 & 2 \\
\hline
\end{tabular}

Table IX. List of reimbursement discount rate in different countries (numbers are rounded)

It was shown that there were not any correlation between price and reimbursement discount rate, and referenced country and reimbursement rate. Average discount rates were similar in all price limits and countries. The distribution depending on the discount rate limits were different in each country (Table VIII and Table IX).

\section{CONCLUSION}

As a result of the reference pricing, which has been applying in Turkey since 2004, pharmaceutical prices has decreased at a large extent. The aim of this study was to define the reference countries which had the most impact on Turkey's pharmaceutical prices.

Generally some countries may have impact on prices more than other countries because of international reference pricing. Therefore pharmaceutical companies may pay more attention to some countries then the others for pricing. This is one of the negative effects of reference pricing.

It was reported that Germany and France were the most two influential countries followed by Italy, Spain and Hungary ahead of a group of six countries of about equal impact on the EU market [3]. On the other hand, though the UK market is only $3 \%$ of the global pharmaceutical market, it is very influential; as already noted, around $25 \%$ of the world market uses UK prices for reference pricing [4]. It was stated that to avoid the negative effects of reference pricing, a weighted index of prices from as many countries as possible should be used to determine the prices in or- der to reduce the direct and indirect impact of individual countries [5].

Reference pricing schemes may lead to control the health expenditures and increase the cost-effectiveness of pharmaceuticals. It was reported that generics and reference prices have lead to decrease prices of statins between 2003 and 2008, increasing the cost-effectiveness of all statins in Spain [6]. In addition, it was shown that most of the countries stated price of pharmaceuticals before the reimbursement decision in order to perform a cost effectiveness analysis [7]. It is know that cost effectiveness analysis is the most important analysis for reimbursement decisions. In the light of these topics, it can be said that pricing is the most important parameter for reimbursement decisions.

The EU is considered as being a single market for pharmaceuticals, depending on Directive $89 / 105 /$ EEC in 1988. International reference pricing will be one of the key parameters for being a "single market" for EU. Due to this, international reference pricing is important for Turkey also as an EU candidate.

These data can be valuable for pharmaceutical companies who wish to launch new pharmaceuticals in Turkey. It has been shown that Italy has the highest impact on the pricing of all pharmaceuticals in Turkey. Even if it was not a reference country, Germany showed to affect pharmaceuticals more than other countries which were also not used for reference pricing. This current analysis is first for the literature. Further analysis is needed in the light of price chances and new launched pharmaceuticals. 


\section{REFERENCES}

1. Kockaya G, K1lıc P. Pharmaceutical Policies and Market Access in Turkey. ISPOR Connections 2012; 18

2. General Directorate of Pharmaceuticals and Pharmacy, Guideline for Pricing Medicinal Products. Ankara, 2007. Available at http://www.iegm.gov.tr/Showing.aspx?process=search\&thelawId=180 (Last accessed October 2011)

3. Lindgren P, Åkerborg O. Analyzing the European External Reference Pricing System Using Spectral Graph Theory. Value in Health 2011; 14: A14-A15

4. Woff J. Pharmaceutical cost-control. Future of Healthcare in Europe, 2011. Available at:http://www.ucl.ac.uk/ european-institute/analysis-publications/analysis/healthcare/Jo_Wolff.p

5. Stargardt T, Schreyögg J. Impact of cross-reference pricing on pharmaceutical prices: manufacturers' pricing strategies and price regulation. Appl Health Econ Health Policy 2006; 5; 235-47

6. Hutton J, Beale S, Kruger J. Pressures faced by people who care for somebody diagnosed with a cardiovascular condition. Value in Health 2009; 12: A344

7. Perard R, Gairy K, Gani R. European pricing and reimbursement update: optimal monetary benefits can depend on which country the process is initiated. Value in Health 2007; 10: A370 